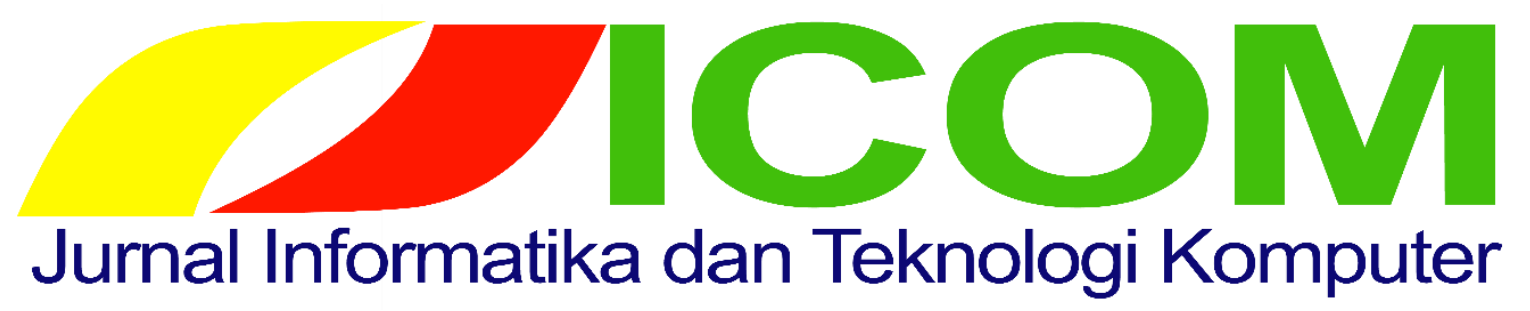

Vol. 02 No. 01 April (2021) $37-42$

E-ISSN :2774-7115 P-ISSN: 2775-2089

\title{
PERANCANGAN SISTEM INFORMASI ALUMNI AKADEMI KEPERAWATAN REFORMASI MAKASSAR BERBASIS ANDROID
}

\author{
Arisona Benyamin Belipati ${ }^{1}$, Florianus Aloysius Nay ${ }^{2}$ \\ ${ }^{1}$ Program Studi Teknik Informatika, Fakultas Teknik dan Perencanaan, Universitas San Pedro \\ ${ }^{2}$ Program Studi Matematika, Fakultas Matematika dan Ilmu Pengetahuan Alam, Universitas San Pedro \\ ${ }^{1}$ tasokstmik09@gmail.com*, ${ }^{2}$ olandnay21juni@gmail.com
}

\begin{abstract}
This study aims to design and implement an android-based alumni information system at the Makassar academy of nursing reform in supporting the management of alumni data into information. This research was conducted at Makassar academy of nursing reform from November 2013 - March 2014. This research used data collection methods with observation, documentation, and interview techniques. The alumni information system in question is an information system about the data of the Makassar academy of nursing reform alumni. The results of this study resulted in an application program for alumni data collection on smartphones based on android. With this application, alumni have the convenience of checking their friends' data during college. This application generates information that is fast, precise and accurate and can be accessed from various places.
\end{abstract}

Keywords: Alumni, Information System, Reform

\begin{abstract}
Abstrak
Penelitian ini bertujuan untuk merancang dan mengimplementasikan sistem informasi alumni berbasis android pada Akademi Keperawatan Reformasi Makassar dalam mendukung pengelolaan data alumni menjadi informasi. Penelitian ini dilaksanakan di Akademi Keperawatan Reformasi Makassar dari bulan november 2013 - maret 2014. Penelitian ini menggunakan metode pengumpulan data dengan teknik observasi, dokumentasi, dan wawancara. Sistem informasi alumni yang dimaksud adalah sistem informasi tentang data-data alumni Akademi Keperawatan Reformasi Makassar. Hasil penelitian ini menghasilkan sebuah program aplikasi pendataan alumni pada smartphone yang berbasis android. Dengan aplikasi ini alumni mendapat kemudahan untuk mengecek data-data dari teman mereka pada saat kuliah. Aplikasi ini menghasilkan informasi yang cepat, tepat dan akurat serta dapat diakses dari berbagai tempat.
\end{abstract}

Kata kunci: Alumni, Sistem Informasi, Reformasi

\section{Pendahuluan}

Alumni Merupakan salah satu bagian dari keberadaan sebuah lembaga pendidikan. keberadaan alumni pada saat ini menjadi salah satu bagian dalam penilaian akreditasi sebuah lembaga pendidikan.Dengan mengetahui keberadaan alumni maka lembaga pendidikan dapat mengukur sejauh mana keberhasilan dalam mendidik hingga siap kerja. Untuk mengetahui keberadaan para alumni dapat menggunakan metode survey yang sering digunakan atau menggunakan kuisioner yang akan dibagikan ketika seseorang lulus atau dengan menggunakan media lain yang dapat digunakan untuk melacak keberadaan Alumni.

Perkembangan teknologi perangkat bergerak, berjalan dengan sangat pesat dan dapat mempermuda pekerjaan tersedia dengan harga yang semakin terjangkau. Hal ini yang dulunya sulit menjadi lebih mudah. Dimana perkembangan perangkat bergerak saat ini menuju ke arah mobile smartphone yang memungkinkan untuk melakukan komunikasi serta terdapat fungsi Personal Digital Assistant (PDA) didalamnya dan memiliki kemampuan layaknya komputer. Pada akhirnya PDA menambahkan fungsi telepon selular pada perangkatnya, begitu pula dengan telepon selular yang menambahkan PDA didalamnya, sehingga hasilnya adalah sebuah mobile smartphone. Salah satu sistem operasi yang sedang berkembang saat ini adalah sistem operasi Android yang diperkenalkan oleh Google. Awalnya Google Inc membeli Android inc, pendatang baru yang membuat piranti lunak untuk ponsel. Mobile smartphone berbasis android di Indonesia saat ini mulai 
membuat jumlah pengguna mobile smartphone di pendataannya masih menggunakan aplikasi microsoft indonesia bertambah banyak. Menurut data, Indonesia office, file-file yang tersimpan pada komputer tentang menempati posisi ke-4 untuk pengguna smartphone alumni belum tertata dengan baik dan data yang terbanyak di dunia.
Android [1], adalah sistem operasi untuk perangkat mobile berbasis linux yang mencakup sistem operasi, midleware dan aplikasi. Android menyediakan platform terbuka bagi para pengembang untuk mencipatakan aplikasi mereka. Awalnya, google Inc. membeli Android Inc. yang merupakan pendatang baru pada pembuatan piranti lunak untuk ponsel/smartphone. tersedia pada file-file hanya menyajikan data lulusan dalam bentuk berita acara sidang dan data usulan ijazah, sehingga laporan data alumni kepada alumni, mahasiswa maupun masyarakat yang memerlukan butuh proses yang cukup lama untuk dapat diberikan. Maka untuk membantu masyarakat kota Makassar pada umumnya serta Alumni dan Mahasiswa AKPER Reformasi pada khususnya dalam mencari data atau informasi tentang Alumni AKPER Reformasi maka Eclipse [1] adalah sebuah IDE (Integrated peneliti tertarik untuk melakukan penelitian yang Development Environment) untuk mengembangkan berjudul "PERANCANGAN SISTEM INFORMASI perangkat lunak dan dapat dijalankan di semua ALUMNI AKPER REFORMASI MAKASSAR platform (platform-independent).Eclipse merupakan BERBASIS ANDROID" yang diharapkan nantinya komunitas open source yang bertujuan menghasilkan dapat membantu dalam mencari informasi tentang data platform pemrograman terbuka. Eclipse terdiri dari alumni AKPER Reformasi Makassar.

framework yang dapat dikembangkan lebih lanjut, peralatan bantu untuk membuat dan memanage 2. Metode Penelitian software sejak awal hingga diluncurkan.

Dalam penelitian ini, peneliti menggunakan jenis Java [2], adalah bahasa pemrograman yang dapat penelitian terapan. Jenis penelitian terapan adalah satu dijalankan di berbagai komputer termasuk telepon jenis penelitian yang hasilnya dapat secara langsung genggam. Bahasa ini awalnya dibuat oleh James diterapkan untuk memecahkan permasalah yang Gosling yang di bantu oleh rekannya seperti Patrick dihadapi. Penelitian terapan ini bertujuan membangun Naugton, Chris Warth, Ed frank, dan Mike Sheridan di “Aplikasi Berupa Sistem Informasi Alumni Berbasis suatu perusahaan perangkat lunak yang bernama sun Android”. Teknik pengumpulan data yang digunakan mycrosystem, pada tahun 1991 bahasa pemrograman ini dalam penelitian ini menggunakan studi literatur mulanya diinisialisasi dengan nama "Oak" namun pada dengan observasi langsung di tempat penelitian. tahun 1995 namanya dirubah menjadi “java”. Alasan Observasi merupakan suatu teknik pengumpulan data utama pembentukan bahasa java adalah untuk membuat yang mempelajari suatu sistem yang sedang berjalan aplikasi-aplikasi yang dapat di letakkan di berbagai khususnya sistem yang berjalan pada AKPER macam perangkat eletronik seperti microwave ovan dan Reformasi Makassar dengan menggunakan alat indra remote control sehingga java bersifat portable atau terutama mata, terhadap kejadian - kejadian yang platform. Java merupakan bahasa pemrograman untuk berlangsung. Dokumentasi merupakan teknik membangun aplikasi pada sistem operasi android.

MySQL (My Structure Query Language) adalah sebuah perangkat lunak sistem manajemen basis data SQL (Database Management System) atau DBMS dari sekian banyak DBMS, seperti Oracle, MS SQL, Postagre SQL, dan lain-lain. MySQL merupakan DBMS yang multithread, multi-user yang bersifat gratis di bawah lisensi GNU General Public License (GPL).

Makassar merupakan salah satu kota terbesar yang ada pengumpulan data yang dilakukan dengan memanfaatkan dokumen-dokumen yang tersedia pada lokasi penelitian khususnya dokumen yang relevan yang menyangkut objek penelitian. Wawancara atau tanya jawab langsung dengan Direktur AKPER Reformasi dan semua staf di AKPER Reformasi yang dianggap mempunyai wewenang dan kemampuan dalam memberikan informasi atau keterangan maupun data lain yang diperlukan yang erat kaitannya dengan penyusunan penelitian ini.

di Kawasan Timur Indonesia yang memiliki banyak 3. Hasil dan Pembahasan perguruan tinggi, salah satunya yaitu Akper Reformasi. Akper Reformasi merupakan akademi keperawatan yang mempunyai visi untuk menjadi lembaga Proses pengembangan sistem yang diusulkan terlebih pendidikan tinggi yang unggul, handal, dan bermartabat dahulu dilakukan analisis terhadap sistem yang sedang menghasilkan insan cerdas dan kompetitif sehingga berjalan. Adapun sistem yang sedang berjalan pada menghantarkan masyarakat Indonesia menjadi bangsa AKPER Reformasi Makassar untuk kegiatan proses yang bersatu, berdaulat dan sejahtera. Sebagai data-data alumni belum efisien dalam hal waktu. perguruan tinggi yang telah ada selama lebih dari Pengolahan data alumni pada AKPER Reformasi sepuluh tahun dan telah mempunyai banyak alumni. Makassar masih manual, semua data alumni dicatat Pada saat ini proses pendataan alumni pada Akper pada sebuah buku besar sehingga dalam mencari data Reformasi masih menggunakan sistem manual yaitu alumni seperti alamat alumni, jumlah alumni 
perangkatan, jumlah alumni yang lanjut studi sangat sulit. Pada pengembangan sistem ini dirancang sebuah bagan alir atau flowchart untuk sistem yang diusulkan yang bisa digunakan untuk membandingkan sistem yang sedang berjalan dengan sistem baru yang akan dibuat.

\subsection{Analisis Kebutuhan Sistem}

Analisis kebutuhan sistem sangat diperlukan dalam mendukung kinerja aplikasi karena kebutuhan sistem akan mendukung tercapainya tujuan suatu aplikasi yang di rancang.

1. Kebutuhan perangkat keras

Agar sebuah sistem dapat berjalan dengan baik dan mempunyai kemampuan yang memadai perangkat keras yang diperlukan dalam pembuatan aplikasi adalah:
a. PC (Personal Computer)
b. Processor intel core
c. Ram 4 giga byte
d. monitor

2. Kebutuhan perangkat lunak

Perangkat lunak yang digunakan dalam mendukung pengoperasian program aplikasi adalah:
a. Java Development Kid (JDK)
b. Eclipse
c. Software Development Kid (SDK)
d. Android Development Tools (ADT)

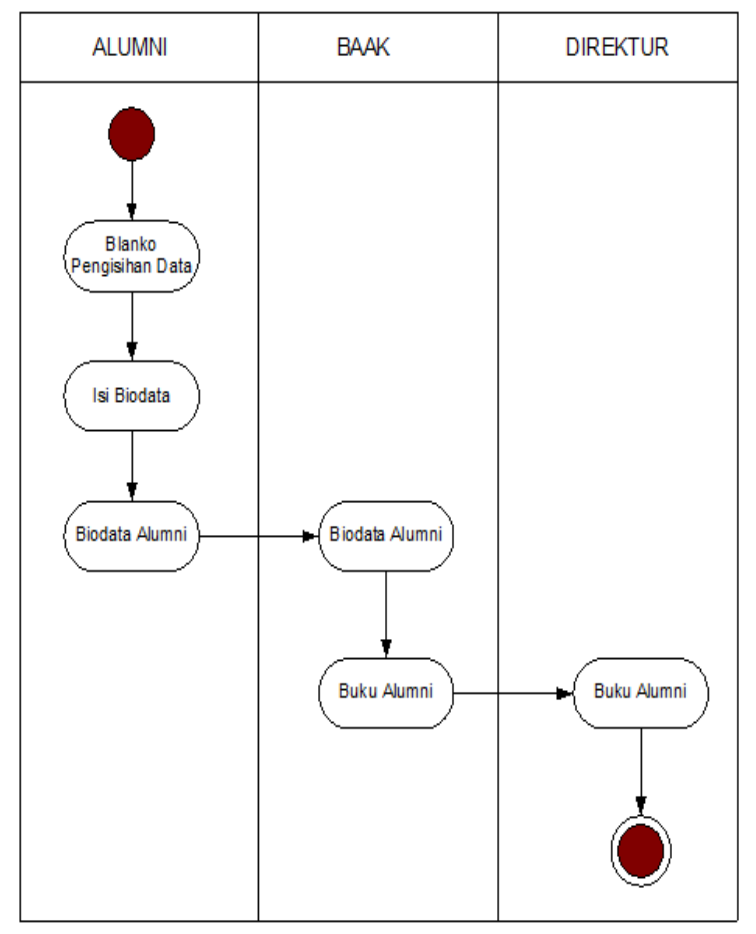

Gambar 1. Sistem yang sedang berjalan

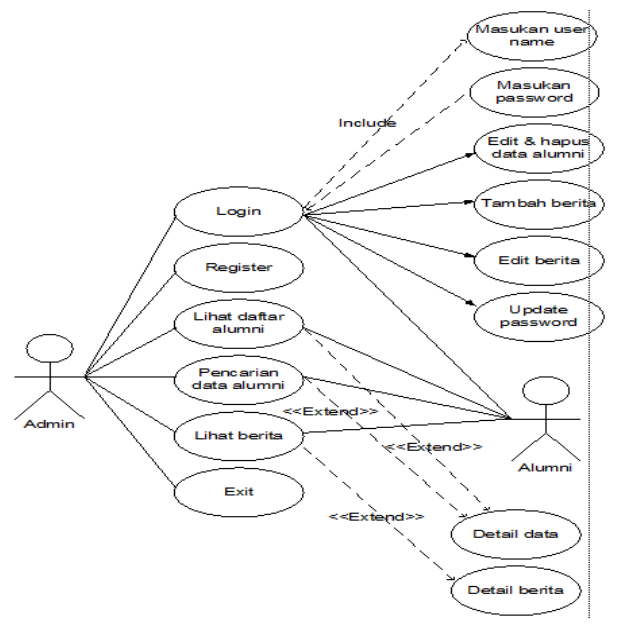

Gambar 2. Sistem yang diusulkan

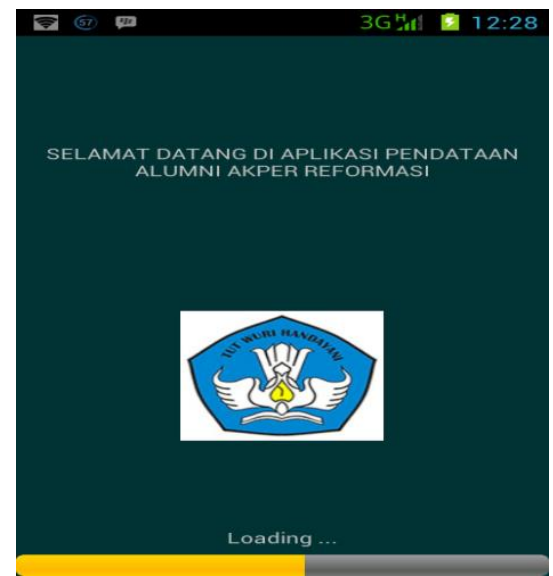

Gambar 3. Halaman Utama

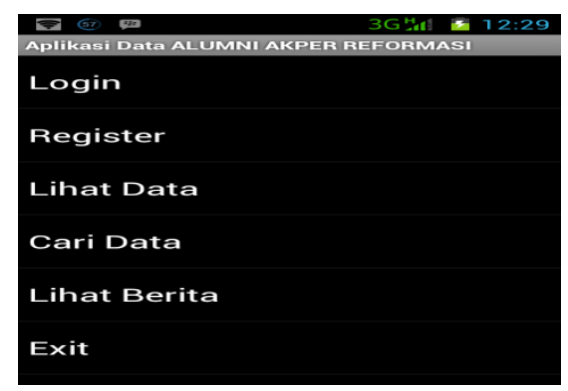

Gambar 4. Tampilan Menu

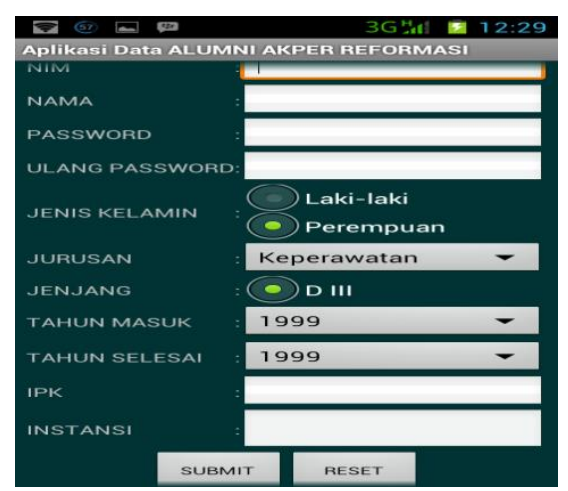

Gambar 5. Tampilan Form Register

Jurnal J-COM (Jurnal Informatika dan Teknologi Komputer) Vol. 02 No. 01 April (2020) 37 - 42 




Gambar 6. Form Login

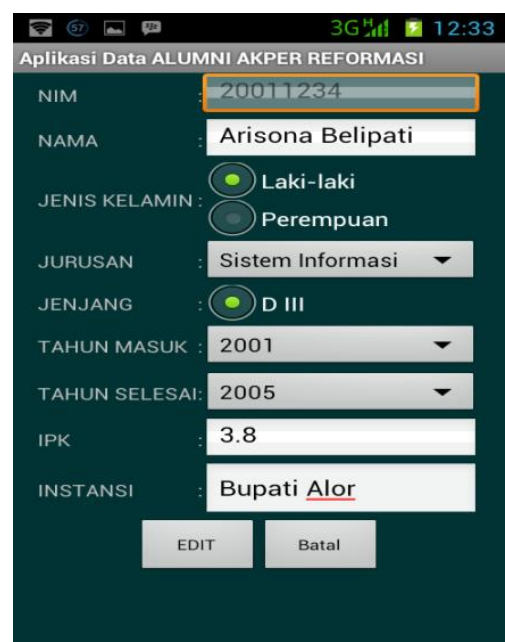

Gambar 7. Form Edit Data

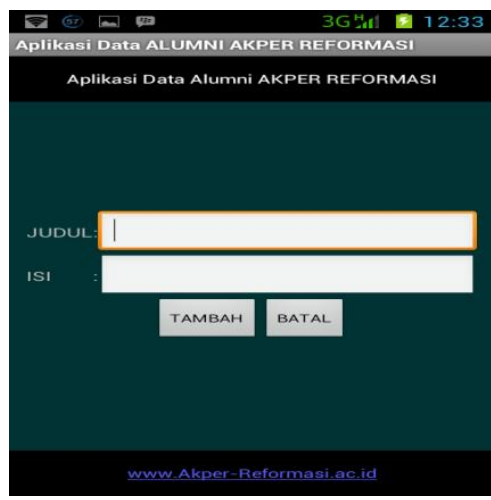

Gambar 8. Tambah Berita



Gambar 9. Daftar Alumni

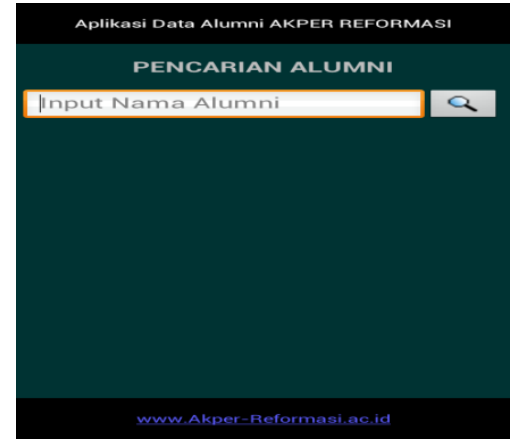

Gambar 10. Cari Data

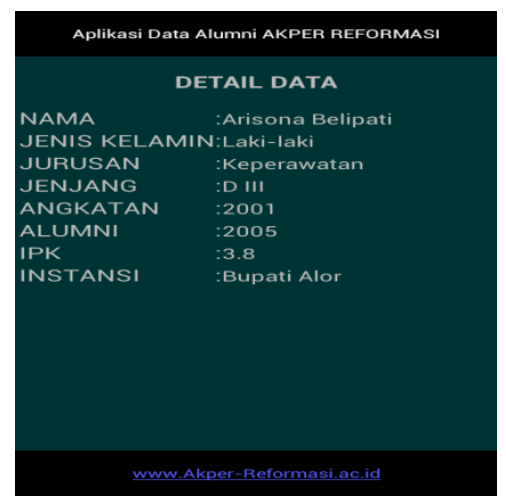

Gambar 11. Detail Data

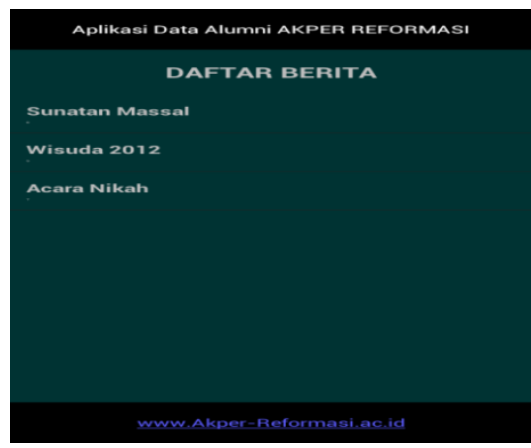

Gambar 12. Daftar Berita

\section{Kesimpulan}

Setelah melakukan penelitian tentang Sistem Informasi Pendataan Alumni Berbasis Android pada Akper Reformasi Makassar, dari hasil pembahasan yang peneliti uraikan sebelumnya, dapat ditarik kesimpulan diantaranya:

1. Untuk menyajikan informasi Alumni Akper Reformasi Makassar yang meliputi penyajian data alumni. Serta informasi lainnya yang dirasa perlu untuk disajikan pada saat dibutuhkan seperti, memudahkan pencarian alumni lama atau baru.

2. Pengembangan sistem informasi berbasis Android ini, maka penanganan terhadap perubahan data baik itu penambahan, pengurangan atau pencarian data akan lebih mudah. 


\section{Saran}

Adapapun saran-saran yang dapat peneliti sampaikan adalah sebagai berikut:

1. Semoga sistem yang peneliti rancang ini dapat dijadikan perbandingan antara sistem yang sedang berjalan dalam menangani masalah pendataan.

2. Agar setiap informasi yang akan diberikan atau publikasi ada baiknya menggunakan sistem yang telah dirancang agar nantinya informasi/data cepat sampai pada user yang membutuhkannya.

3. Diharapkan dengan adanya sistem informasi berbasis Android dapat lebih membantu pada Akper Reformasi Makassar tidak sebatas sistem yangdirancang, akan tetapi perubahanperubahan yang dirasa perlu untuk mempromosikan Akper Reformasi Makassar pada masyarakat.

\section{Daftar Rujukan}

[1] Nazruddin Safaat H, 2012. Pemrograman Aplikasi Mobile Smartphone dan Tablet Pc Berbasis Android, Bandung: Informatika.

[2] Budi Raharjo, Imam Heryanto, \& Arif Haryanto, 2012. Mudah Belajar Java, Bandung : Informatika.

[3] Hillman Akhyar Damanik, 2011, Sekilas UML (Unified Modeling Language),
(Online),[http://hillmanakhyarddamanik.wordpress.com/, diakses 10 Oktober 2013]

4] Noprianto, 2007, Sqlite, (Online), [http://arrohman.files.wordpress.com/, diakses 3 November 2013]

5] Resh Android, 2010, Arsitektur dan Aplikasi Android, (Online), [http://androidmakassar.com/, diakses 1 Oktober 2013]

[6] Sri Dharwiyanti, 2005, kosep Dasar Sistem, (Online), disk1, [http://elib.unikom.ac.id/, diakses 1 Oktober 2013] 
